\title{
Produtividade e valor nutritivo de pastos consorciados com diferentes espécies de leguminosas
}

\author{
Productivity and nutritive value of mixed pastures with different legume species
}

\author{
Clair Jorge Olivo ${ }^{\mathrm{I}}$ José Laerte NörnbergII Gilmar Roberto Meinerz ${ }^{\mathrm{II}}$ Carlos Alberto Agnolin ${ }^{\mathrm{III}}$

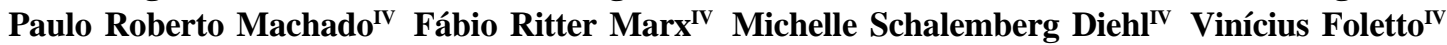 \\ Priscila Flôres Aguirre $^{\mathrm{IV}}$ Tiago Luis da Ros Araújo ${ }^{\mathrm{IV}}$ Cláudia Marques de Bem ${ }^{\mathrm{IV}}$ \\ Juliano Costa dos Santos ${ }^{\mathrm{IV}}$
}

\section{RESUMO}

O objetivo desta pesquisa foi avaliar a produtividade e o valor nutritivo de dois sistemas forrageiros (SF) constituídos por capim elefante (CE), azevém (AZ), trevo branco (TB) e espécies de crescimento espontâneo (ECE), como SF1; e CE + $A Z+$ amendoim forrageiro $(A F)+E C E$, como SF2. O CE foi estabelecido em linhas espaçadas a cada quatro metros. Entre elas, foi estabelecido azevém, durante o período hibernal, permitindo-se o desenvolvimento de ECE no período estival. Para avaliação, foram utilizadas vacas da raça Holandesa e o método de pastejo foi o rotacionado. Avaliaram-se a massa de forragem inicial (MFI) e a composição botânica e estrutural dos pastos. Para as estimativas de valor nutritivo, foram feitas amostragens simulando o pastejo e analisados a fibra em detergente neutro (FDN), fibra em detergente ácido (FDA), proteína bruta $(P B)$, digestibilidade in vitro da matéria seca (DIVMS) e digestibilidade in vitro da matéria orgânica (DIVMO). O delineamento experimental foi o inteiramente casualizado com dois tratamentos e duas repetições, em parcelas subdivididas no tempo. Os valores médios de massa de forragem inicial e da carga animal foram similares entre os SF. Observouse resultado superior para o teor médio de $P B$ da forragem do SF2. O uso do azevém, das leguminosas e das espécies de crescimento espontâneo em consórcio com o CE permite manter massa de forragem uniforme no decorrer dos pastejos.

Palavras-chave: Arachis pintoi, composição química, massa de forragem, Lolium multiflorum, Pennisetum purpureum, Trifolium repens.

\section{ABSTRACT}

The objective of this research was to evaluate the productivity and nutritive value of two pasture-based systems
(PS) with elephant grass $(E G)+$ ryegrass $(R G)+$ white clover (WC) + spontaneous growing species (SGS), for PS1; and EG $+R G+$ forage peanut (FP) + SGS, for PS2. EG was established in rows spaced by four meters. Ryegrass was seeding in the space between rows during cool-season and development of SGS was permitted in the warm-season. Holstein cows under rotational grazing were used in the evaluation. The initial forage mass (IFM), the botanical composition and the structural components were evaluated. Samples from hand-plucking method were collected to analyze neutral detergent fiber (NDF), acid detergent fiber (ADF), crude protein (CP), in vitro dry matter digestibility (IVDMD) and in vitro organic matter digestibility (IVOMD). The experimental design used was completely randomized with two treatments, two repetitions in complete split-plot time. The mean values of initial forage mass and stocking rate were similar among PS. Superior results were found for mean of CP in PS2. The use of ryegrass, legumes and spontaneous growing species mixed to EG allow the forage mass to be uniform during the grazing pastures.

Key words: Arachis pintoi, chemical composition, forage mass, Lolium multiflorum, Pennisetum purpureum, Trifolium repens.

\section{INTRODUÇÃO}

O uso de consórcios forrageiros, especialmente com leguminosas, pode contribuir para a otimização dos recursos envolvidos, possibilitando um maior equilíbrio na dieta dos animais no decorrer do ano (SANTOS et al., 2002), além de aumentar o

IDepartamento de Zootecnia, Universidade Federal de Santa Maria (UFSM), 97105-900, Santa Maria, RS, Brasil. E-mail: clairo@smail.ufsm.br. Autor para correspondência.

IIDepartamento de Ciência e Tecnologia de Alimentos, UFSM, Santa Maria, RS, Brasil.

IIIPrograma de Pós-graduação em Zootecnia, UFSM, Santa Maria, RS, Brasil.

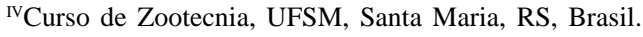


período de pastejo, resultando em melhor rendimento animal (ASSMANN et al., 2004). Outros aspectos favoráveis do uso das leguminosas são a melhoria das condições de solo e a ciclagem de nutrientes (RAO \& KERRIGE, 1994) e do rendimento animal com o decorrer do tempo (LOURENÇO et al., 1987).

Dentre as espécies de leguminosas indicadas para o consórcio com gramíneas tropicais, destaca-se o amendoim forrageiro, suportando elevadas taxas de lotação. Já para a associação com gramíneas temperadas, o trevo branco é uma boa opção para compor misturas forrageiras. No entanto, em condições de clima subtropical, a persistência dessas leguminosas é comprometida pelo estabelecimento lento e dificuldades de manejo. A ocorrência de verões quentes e secos e de invernos rigorosos, com elevado número de geadas, pode comprometer o desenvolvimento do trevo branco e do amendoim forrageiro, respectivamente (SCHEFFER-BASSO et al., 2005; PERIN et al., 2000).

Embora haja benefícios do uso das leguminosas consorciadas às gramíneas, trabalhos sob condições de pastejo com bovinos leiteiros, são escassos. Assim, estudou-se a produtividade e o valor nutritivo de pastagens consorciadas constituídas por capim elefante, azevém e amendoim forrageiro ou trevo branco.

\section{MATERIAL E MÉTODOS}

Este trabalho foi conduzido no Laboratório de Bovinocultura de Leite, pertencente ao Departamento de Zootecnia e as análises laboratoriais foram feitas no Núcleo Integrado de Desenvolvimento em Análises Laboratoriais (NIDAL), da Universidade Federal de Santa Maria (UFSM), localizada na região da Depressão Central (Santa Maria - RS) a 29 43' de latitude Sul e $53^{\circ} 42^{\prime}$ de longitude Oeste, com clima subtropical úmido. Os valores da precipitação anual variam de 1300 a 1800mm e a temperatura média é de $21,4^{\circ} \mathrm{C}$. A temperatura média do período experimental foi de $19,9^{\circ} \mathrm{C}$, com ocorrência de cinco geadas em agosto, e a precipitação pluviométrica foi de $1889 \mathrm{~mm}$. O solo é classificado como argissolo vermelho distrófico arênico.

Os tratamentos foram constituídos por duas pastagens formadas por capim elefante, azevém e espécies de crescimento espontâneo em consórcio com diferentes espécies de leguminosas. A área utilizada (1,0ha) foi dividida em quatro piquetes ( 0,25 ha cada), todos com capim elefante (Pennisetum purpureum Schum.) cv. 'Merckeron Pinda', já estabelecidos em linhas com espaçamento de $4 \mathrm{~m}$. Nas entrelinhas, em metade da área, o amendoim forrageiro (Arachis pintoi
Krap. \& Greg.), cv. 'Amarillo', foi implantado em dezembro de 2004, com densidade de semeadura de $12 \mathrm{~kg} \mathrm{ha}^{-1}$. Na outra metade, em maio de 2006, mediante escarificação do solo, foi estabelecido o trevo branco (Trifolium repens L.), cv. 'Yi', em densidade de $4 \mathrm{~kg} \mathrm{ha}^{-1}$. Em ambos os tratamentos, o azevém (Lolium multiflorum Lam.), cv. 'Comum', com densidade de $40 \mathrm{~kg} \mathrm{ha}^{-1}$, foi estabelecido nas entrelinhas por sobressemeadura. Em agosto, o capim elefante foi roçado visando a uniformizar as linhas. No período estival, permitiu-se o desenvolvimento de espécies de crescimento espontâneo. No estabelecimento e manejo dos pastos, não foram utilizados pesticidas.

Para adubação, foram utilizados $40 \mathrm{~kg} \mathrm{ha}^{-1}$, tanto de $\mathrm{P}_{2} \mathrm{O}_{5}$, quanto de $\mathrm{K}_{2} \mathrm{O}$, conforme recomendação de análise de solo (COMISSÃO DE QUÍMICA E FERTILIDADE DO SOLO, 2004). Como adubação de cobertura, foram utilizados $100 \mathrm{~kg} \mathrm{ha}^{-1} \mathrm{de} \mathrm{N}$ sob a forma de ureia, parcelado em cinco aplicações.

O critério de utilização da pastagem durante o período hibernal teve como base o desenvolvimento do azevém, quando este se encontrava próximo a $20 \mathrm{~cm}$ de altura. No período estival, foi a altura do capim elefante, entre 80 e $100 \mathrm{~cm}$. Os piquetes de cada tratamento foram pastejados simultaneamente. Antecedendo a entrada dos animais, estimou-se a massa de forragem mediante a técnica por dupla amostragem (WILM et al., 1944), com 20 estimativas visuais e cinco cortes por piquete, em cada pastejo. No capim elefante, os cortes foram feitos a $50 \mathrm{~cm}$ do solo e, nas entrelinhas, rente ao solo. As amostras foram pesadas e homogeneizadas, sendo retirada uma subamostra para estimativa das composições botânica da pastagem e estrutural do capim elefante, do azevém e das leguminosas, que foram posteriormente secas em estufa para determinação da matéria parcialmente seca. Na estimativa da massa de forragem, consideraram-se $25 \%$ da área ocupada pelo capim elefante e $75 \%$ ocupada pelas espécies presentes nas entrelinhas.

Para a avaliação, foram usadas vacas em lactação da raça Holandesa, com peso médio de $514 \pm 30 \mathrm{~kg}$ e produção média de $16,41 \pm 4,26 \mathrm{~kg} \mathrm{dia}^{-1}$, recebendo uma complementação alimentar diária de $4 \mathrm{~kg}$ de concentrado com $20 \%$ de proteína bruta, mais $1 \mathrm{~kg}$ de MS de silagem de sorgo, nos pastejos efetuados entre os meses de agosto e outubro, fornecidos após as ordenhas (manhã e tarde). As vacas permaneceram nas pastagens das $9 \mathrm{~h}$ às $16 \mathrm{~h}$ e das $18 \mathrm{~h}$ às $7 \mathrm{~h}$, tendo a sua disposição sombra, água e sal mineralizado.

Para determinar o valor nutritivo, foram retiradas, em cada pastejo, amostras de simulação de pastejo (EUCLIDES et al., 1992) e, isoladamente, do capim elefante, do material presente nas entrelinhas, 
no momento da entrada e da saída dos animais, as quais foram secas, moídas e posteriormente analisadas para determinação do teor de PB, pelo método de Kjeldahl (AOAC, 1984), FDN(VAN SOEST et al., 1991), DIVMS eDIVMO,(TILLEY \& TERRY, 1963).

Para estimar a carga animal, manteve-se oferta de forragem de 8 e $4 \mathrm{~kg}$ MS por $100 \mathrm{~kg}$ de PV para a massa de forragem na entrelinha e para a massa de lâminas foliares do capim elefante, respectivamente. $\mathrm{O}$ método de pastejo utilizado foi o rotacionado, com dois dias de ocupação. A carga animal média foi calculada dividindo-se a soma das cargas instantâneas pelo número de dias de avaliação dos pastos.

O delineamento experimental utilizado foi o inteiramente casualizado com dois tratamentos (sistemas forrageiros), duas repetições de área (piquetes), com medidas repetidas no tempo (ciclos de pastejo), avaliadas de forma independente. Os dados foram submetidos à análise de variância e as médias comparadas pelo teste $\mathrm{F}$, em nível de $5 \%$ de probabilidade do erro e de correlação, através do coeficiente de Pearson. As análises foram efetuadas com auxílio do pacote estatístico SAS (1997).

O modelo estatístico referente à análise das variáveis estudadas da pastagem foi representado por: $Y i j=m+T i+R j(T i)+\varepsilon i j$, em que: Yij representa as variáveis dependentes; i, índice de tratamentos (sistemas forrageiros); j, índice de repetições (piquetes); m é a média de todas as observações; Ti é o efeito dos tratamentos; Rj(Ti) é o efeito de repetição dentro dos tratamentos (erro a); $\varepsilon$ ijk é o erro experimental residual (erro b).

A avaliação dos pastos foi feita entre 07/08/ 2006 e 28/03/2007, perfazendo um total de 234 dias, sendo de 07/08/06 a 26/03/07 (232 dias) para o sistema constituído por amendoim forrageiro e de 13/08/06 a 28/ 03/07 (228 dias) para o sistema envolvendo o trevo branco. Foram conduzidos seis pastejos, três no período hibernal e três no período estival. O tempo de ocupação de cada ciclo de pastejo variou de um a dois dias e o descanso foi de 39 e 44 dias para os períodos hibernal (caracterizado pelo período de desenvolvimento do azevém) e estival, respectivamente.

\section{RESULTADOS E DISCUSSÃO}

A participação do capim elefante, que ocupou 25\% da área, foi de 64,1 e 59,3\% da massa de forragem, para os sistemas constituídos por trevo branco e amendoim forrageiro, respectivamente (Tabela 1). O valor médio da massa de forragem inicial, próximo a $3,1 \mathrm{t} \mathrm{ha}{ }^{-1}$, é semelhante à disponibilidade encontrada por RESTLE et al. (2002), de 3,6t ha-1 ${ }^{-1}$ na mesma região, em pastagem da cv. 'Taiwan A-146', estabelecida de forma exclusiva, avaliado entre dezembro e abril, mas adubado com $500 \mathrm{~kg} \mathrm{ha}^{-1}$ de nitrogênio.

Destaca-se, no presente trabalho, que, mesmo com a ocorrência de poucas geadas, caracterizando um inverno mais ameno, o capim elefante manteve participação significativa em todo período hibernal. Essa contribuição, especialmente de biomassa de lâminas foliares, embora menor que a produção do período estival, é importante, pois as forrageiras de inverno normalmente produzem menos forragem, equilibrando, assim, a oferta de forragem.

Analisando-se o capim elefante no decorrer dos pastejos, observa-se que houve diferença $(\mathrm{P}<0,05)$ na avaliação efetuada em outubro, com maior valor no sistema constituído por amendoim forrageiro. É possível que tenha havido contribuição dessa leguminosa à gramínea, devido à ação do frio e das geadas, especialmente, havendo perda dos componentes estruturais da planta, e, consequentemente, mecanismos de reciclagem que ocorrem subterraneamente, por meio da senescência de raízes e nódulos, e, superficialmente, através da degradação de seus resíduos (CADISCH et al., 1994). Resposta similar pode ter ocorrido no pastejo efetuado em fevereiro, considerando o declínio do trevo branco, com liberação de nutrientes à gramínea acompanhante.

Considerando-se os valores médios dos pastejos, não houve diferença entre os sistemas forrageiros ( $\mathrm{P}>0,05)$ para a massa de forragem inicial, de lâminas foliares e de colmo + bainha. Para a massa de forragem presente entre as linhas de capim elefante, observa-se que não houve diferença entre os sistemas para os componentes botânicos e estruturais avaliados $(\mathrm{P}>0,05)$.

Quanto às leguminosas, verificou-se que a participação média do trevo branco e do amendoim forrageiro foi de 6,4 e $30,4 \%$ de massa de forragem presente nas entrelinhas, respectivamente. Com o trevo branco, observou-se um comportamento típico com ápice da produção de massa de forragem nos pastejos efetuados no início do período estival, verificando-se comprometimento dessa forrageira em épocas mais quentes, confirmando as avaliações efetuadas no Rio Grande do Sul por SCHEFFER-BASSO et al. (2005).

A participação do trevo branco foi inferior às verificadas por OLIVO et al. (2009), que, trabalhando com sistema forrageiro semelhante, verificaram um valor de massa de forragem inicial de $260 \mathrm{~kg} \mathrm{ha}^{-1}$ de MS (média de nove pastejos).

Para o amendoim forrageiro, verificou-se maior participação nos pastejos efetuados no período estival com ápice da produção na avaliação conduzida em março. Esse comportamento aponta que essa leguminosa pode ser importante na manutenção do valor 
Tabela 1 - Massa de forragem inicial e carga animal de dois sistemas forrageiros (SF). 2006-2007.

\begin{tabular}{|c|c|c|c|c|c|c|c|c|c|}
\hline \multirow{2}{*}{ Variáveis } & \multirow[b]{2}{*}{$\mathrm{SF}^{1}$} & \multicolumn{6}{|c|}{ - } & \multirow{2}{*}{ Média } & \multirow{2}{*}{ CV $(\%)$} \\
\hline & & $1^{\underline{o}}(\mathrm{Jul} / 06)$ & $2^{\circ}$ (Set/06) & $3^{\circ}$ (Out/06) & $4^{\circ}(\mathrm{Jan} / 07)$ & $5^{\circ}(\mathrm{Fev} / 07)$ & $6^{\circ}(\mathrm{Mar} / 07)$ & & \\
\hline \multirow{3}{*}{ Massa de forragem } & & & --------C & im elefante ( & ha $^{-1}$ de MS) & & & & --- \\
\hline & 1 & 3663 & 3351 & $3424^{\mathrm{b}}$ & 1351 & $3036^{\mathrm{a}}$ & 4710 & 3256 & \multirow{2}{*}{16,36} \\
\hline & 2 & 3857 & 4018 & $3931^{\mathrm{a}}$ & 919 & $1223^{b}$ & 4047 & 3005 & \\
\hline \multirow{2}{*}{ Lâminas foliares } & 1 & 364 & 673 & $473^{\mathrm{b}}$ & 1103 & 2190 & 2128 & 1155 & \multirow{2}{*}{25,16} \\
\hline & 2 & 351 & 883 & $841^{\mathrm{a}}$ & 832 & 779 & 1041 & 1011 & \\
\hline \multirow{2}{*}{ Colmo + bainha } & 1 & 2290 & 1783 & 1075 & 246 & 814 & 2518 & 1621 & \multirow{2}{*}{26,47} \\
\hline & 2 & 2439 & 2208 & 2179 & 122 & 443 & 2648 & 1450 & \\
\hline \multirow{3}{*}{ Material senescente } & 1 & 824 & 894 & 875 & 0 & 274 & 61 & $488^{\mathrm{b}}$ & \multirow{2}{*}{28,78} \\
\hline & 2 & 1065 & 925 & 909 & 0 & 657 & 356 & $652^{\mathrm{a}}$ & \\
\hline & & & ---------- & Entrelinha (kg & $\mathrm{a}^{-1}$ de MS) - & & & & \multirow{3}{*}{18,36} \\
\hline \multirow{2}{*}{ Massa de forragem } & 1 & 846 & 1227 & 1265 & 1393 & 3098 & 3301 & 2262 & \\
\hline & 2 & 973 & 1034 & 1544 & 2562 & 3608 & 2988 & 2533 & \\
\hline \multirow{2}{*}{ Lâminas foliares } & 1 & 458 & 411 & 259 & - & - & - & 376 & \multirow{2}{*}{56,71} \\
\hline & 2 & 436 & 400 & 195 & - & - & - & 310 & \\
\hline \multirow{2}{*}{ Colmo + bainha } & 1 & 134 & 573 & 598 & - & - & - & 423 & \multirow{2}{*}{61,11} \\
\hline & 2 & 279 & 441 & 753 & - & - & - & 491 & \\
\hline \multirow{2}{*}{ Material senescente } & 1 & 33 & 15 & 136 & 387 & 111 & 424 & 184 & \multirow{2}{*}{58,22} \\
\hline & 2 & 94 & 57 & 220 & 286 & 89 & 159 & 151 & \\
\hline ТВ & 1 & 129 & 154 & 140 & 44 & 0 & 0 & 94 & - \\
\hline $\mathrm{AF}$ & 2 & 93 & 55 & 248 & 1310 & 1443 & 615 & 627 & - \\
\hline \multirow{3}{*}{ Outras espécies } & 1 & 92 & 74 & 132 & 962 & 2987 & 2877 & 1185 & \multirow{2}{*}{63,55} \\
\hline & 2 & 71 & 81 & 128 & 966 & 2076 & 2214 & 954 & \\
\hline & & & & --Total (kg h & de MS) - & & & & \\
\hline \multirow{2}{*}{ Massa de forragem } & 1 & 4509 & $4578^{b}$ & $4689^{b}$ & 2744 & 6134 & 8011 & 5518 & 12,35 \\
\hline & 2 & 4830 & $5052^{\mathrm{a}}$ & $5475^{a}$ & 3481 & 4831 & 7035 & 5538 & 12,35 \\
\hline L âminas foliares & 1 & 822 & 1084 & 732 & 1103 & 2190 & 2128 & 1343 & 3512 \\
\hline Laminas ionlares & 2 & 787 & 1283 & 1036 & 832 & 779 & 1041 & 960 & 35,12 \\
\hline Colmo + Rainha & 1 & 2424 & 2356 & 1673 & 246 & 814 & 2518 & 1672 & 12 \\
\hline Colmo + Bainha & 2 & 2718 & 2649 & 2932 & 122 & 443 & 2648 & 1919 & 42,14 \\
\hline Material senescente & 1 & 857 & 909 & 1011 & 387 & 385 & 485 & 672 & 4510 \\
\hline Materıal senescente & 2 & 1159 & 982 & 1129 & 286 & 746 & 515 & 803 & 45,10 \\
\hline ТВ & 1 & 129 & 154 & 140 & 44 & 0 & 0 & 94 & - \\
\hline $\mathrm{AF}$ & 2 & 93 & 55 & 248 & 1310 & 1443 & 615 & 627 & - \\
\hline Outras ecnécijec & 1 & 92 & 74 & 132 & 962 & 2987 & 2877 & 1185 & 6355 \\
\hline Outras especies & 2 & 71 & 81 & 128 & 966 & 2076 & 2214 & 954 & 63,ל5 \\
\hline & & & ------Carga & nimal ( $k g$ ha & de peso corpo & l) --_-- - & & & \\
\hline Carga instantânea & 1 & 14600 & 18668 & 22864 & 26400 & 49436 & 43380 & 29224 & 17,23 \\
\hline & 2 & 14732 & 22316 & 24588 & 37972 & 49192 & 44672 & 32244 & \\
\hline
\end{tabular}

1SF1 = capim elefante $(\mathrm{CE})$ + azevém $(\mathrm{AZ})$ + espécies de crescimento espontâneo (ECE) + trevo branco (TB); SF2 = CE + AZ + ECE + amendoim forrageiro (AF). $\mathrm{CV}=$ Coeficiente de variação. 'a b' médias seguidas por letras distintas, na coluna, diferem entre si $(\mathrm{P}<0,05)$. 
nutritivo da forragem no outono (SANTOS et al., 2002), especialmente em regiões subtropicais, que, tradicionalmente, apresentam problemas típicos de escassez de forragem nessa época (RESTLE et al., 2002).

Considerando-se, no entanto, a participação média das leguminosas na massa de forragem total, os valores foram de 3,6 e 20,9\%, respectivamente, para o trevo branco e o amendoim forrageiro. Estudo conduzido por CADISCH et al. (1994), com consórcio de Brachiaria humidícola e Calopogonium mucunoides, sugere uma proporção entre 13 e $23 \%$ de leguminosa como condição necessária para manter a sustentabilidade do sistema, enquanto THOMAS (1992), a partir de modelos teóricos, indica uma participação de 30\%. A partir dessas indicações, observa-se que somente o amendoim forrageiro atingiu as proporções indicadas, considerou-se a média da massa de forragem verificada nos pastejos efetuados no período estival. A fração constituída por outras espécies, em maioria de ciclo estival, confirma a elevação dos valores de massa de forragem nesse período, com destaque para Paspalum conjugatum, papuã (Urochloa plantaginea), milhã (Digitaria sanguinalis), guanxuma (Sida santaremnensis), erva-de-bicho (Polygonum persicaria) e a buva (Conyza bonariensis).

Para carga animal, não houve diferença entre os sistemas forrageiros, tanto entre pastejos quanto na média das avaliações, estando associada à massa de forragem $(0,6620 ; \mathrm{P}=0,0004)$. O valor médio foi de $1,75 \mathrm{UA} \mathrm{ha}^{-1}$. Cargas similares às deste trabalho foram obtidas por SOBCZAK et al. (2005), no Rio Grande do Sul, com a mesma cultivar, usando sistema similar com mistura de capim elefante e aveia preta cv. 'Comum'. Valores superiores foram observados por GONZALES et al. (1996), que obtiveram uma lotação de 2,4UA ha-1 em pastagem de capim estrela (Cynodon nlenfluensis) cv. 'Roxo', consorciado com amendoim forrageiro.

Para as variáveis de valor nutritivo, não houve diferença entre os sistemas para o capim elefante, considerando as médias dos pastejos (Tabela 2). Observa-se que os teores médios de PB do capim elefante, verificados no período hibernal, de 17,71 e 16,09\%, para os sistemas consorciados com trevo branco e amendoim forrageiro, respectivamente, são mais elevados em relação aos teores observados no período estival, confirmado pela associação da biomassa de folhas dessa forrageira com o teor de $\mathrm{PB}(-0,6196 ; \mathrm{P}=0,0012)$, condição também apontada por outros autores (TOWNSEND et al., 1994; OLIVO et al., 2009).

Avaliando-se o valor nutritivo da forragem presente entre as linhas de capim elefante (Tabela 2), houve diferença $(\mathrm{P}<0,05)$ para o teor de $\mathrm{PB}$, com superioridade para o sistema constituído por amendoim forrageiro. Esse resultado deve-se à presença dessa leguminosa em todas as avaliações, além de apresentar maior proporção em relação ao trevo branco em quatro dos seis pastejos. Comparando-se os períodos, observa-se que, no hibernal, as médias foram mais elevadas, sendo de 17,7 e de $16,1 \%$ para sistemas constituídos por trevo branco e amendoim forrageiro, notadamente, devido à presença do azevém (Tabela 1), que, normalmente, apresenta melhor valor nutritivo, se comparado com gramíneas de ciclo estival. Teor similar ao do presente trabalho, de 18,16\%, foi observado por OLIVO et al. (2007) em mistura de aveia e azevém manejada sob princípios agroecológicos. Já no período estival, os menores teores de PB foram observados no sistema constituído por trevo branco, devido à baixa participação ou ausência dessa leguminosa na composição do pasto. Esse resultado pode ter influenciado no menor $(\mathrm{P}<0,05)$ teor médio de DIVMS verificado nesse sistema. Para os teores de FDN e FDA, houve similaridade entre os pastos, considerando a média das avaliações. Os valores mais baixos dessas variáveis, observados no período hibernal, devem-se à presença predominante do azevém. Usando metodologia similar à do presente trabalho, com misturas forrageiras de inverno e de verão, SOBCZAK et al. (2005) e OLIVO et al. (2009) verificaram teores de 58,6 e 64,15\% de FDN, respectivamente, para os períodos hibernal e estival.

Para o pasto (capim elefante + material presente nas entrelinhas), considerando a média das avaliações, houve diferença $(\mathrm{P}<0,05)$ somente para o teor de $\mathrm{PB}$, com valor mais elevado no sistema constituído por amendoim forrageiro. Esse resultado deve-se à maior participação dessa leguminosa na composição do pasto nos pastejos efetuados no período estival (Tabela 1), e evidenciado pelas diferenças observadas no teor proteico da forragem nas avaliações feitas em fevereiro e março. Valores similares de proteína, de 15,69 e 14,62\%, foram obtidos por OLIVO et al. (2009), ao avaliarem o trevo branco e o amendoim forrageiro, respectivamente, em consórcio com gramíneas. Para as demais variáveis, observa-se um maior equilíbrio entre os pastejos, devido, em maior parte, à composição variada do pasto, constituído por forrageiras dos ciclos hibernal e estival. MEINERZ et al. (2008), avaliando o capim elefante em consórcio com azevém e espécies de crescimento espontâneo, sob manejo agroecológico, obtiveram teores qualitativamente melhores, com médias de FDN, DIVMS e DIVMO de 50,44; 70,52 e 71,10\%, respectivamente.

\section{CONCLUSÃO}

A produção de massa de forragem e a carga animal são semelhantes entre os sistemas forrageiros. 
Tabela 2 - Percentuais de matéria orgânica (MO), proteína bruta (PB), fibra em detergente neutro (FDN) e ácido (FDA), digestibilidade in vitro da matéria seca (DIVMS) e orgânica (DIVMO) de dois sistemas forrageiros (SF). 2006-2007.

\begin{tabular}{|c|c|c|c|c|c|c|c|c|c|}
\hline Variáveis & $\mathrm{SF}^{1}$ & $1^{\mathrm{o}}(\mathrm{Jul} / 06)$ & $2^{\underline{0}}($ Set/06) & $3^{\circ}(\mathrm{Out} / 06)$ & 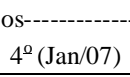 & $5^{\circ}(\mathrm{Fev} / 07)$ & 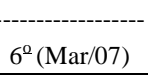 & Média & CV (\%) \\
\hline & & & & -Capir & lefante-- & & & & \\
\hline \multirow{2}{*}{$\mathrm{MO}$} & 1 & 86,89 & 87,30 & 87,95 & 89,10 & 90,81 & 88,92 & 88,49 & \multirow{2}{*}{1,45} \\
\hline & 2 & 87,27 & 87,16 & 88,14 & 88,79 & 89,87 & 88,49 & 88,28 & \\
\hline \multirow{2}{*}{ PB } & 1 & 17,49 & 19,01 & $16,62 a$ & 12,47 & 9,54 & 12,90 & 14,67 & \multirow{2}{*}{6,96} \\
\hline & 2 & 16,10 & 17,51 & $14,66 \mathrm{~b}$ & 13,51 & 12,55 & 14,99 & 14,88 & \\
\hline \multirow{2}{*}{ FDNc } & 1 & 69,07 & 63,36 & 62,99 & $70,83^{\mathrm{a}}$ & 76,13 & 73,49 & 69,31 & \multirow{2}{*}{4,95} \\
\hline & 2 & 70,39 & 63,65 & 64,60 & $66,60^{\mathrm{b}}$ & 72,26 & 72,43 & 68,32 & \\
\hline \multirow{2}{*}{ FDAc } & 1 & 33,08 & 30,21 & 30,27 & 34,72 & 37,00 & 36,57 & 33,64 & \multirow{2}{*}{5,33} \\
\hline & 2 & 34,90 & 30,96 & 30,79 & 31,52 & 34,97 & 35,56 & 33,11 & \\
\hline \multirow{2}{*}{ DIVMS } & 1 & 65,01 & 63,66 & 67,28 & 68,74 & 64,88 & $62,58^{\mathrm{b}}$ & 65,36 & \multirow{2}{*}{1,96} \\
\hline & 2 & 62,61 & 62,44 & 69,22 & 66,65 & 66,02 & $66,66^{\mathrm{a}}$ & 65,60 & \\
\hline \multirow{2}{*}{ DIVMO } & 1 & $68,99^{\mathrm{a}}$ & 67,93 & 72,38 & 72,79 & 66,65 & 66,22 & 69,16 & \multirow{2}{*}{2,19} \\
\hline & 2 & $66,84^{\mathrm{b}}$ & 67,80 & 72,92 & 70,58 & 69,04 & 69,30 & 69,41 & \\
\hline \multirow{2}{*}{$\mathrm{MO}$} & 1 & 86,90 & 84,13 & 88,43 & 86,03 & 98,18 & 89,71 & 87,89 & \multirow{2}{*}{3,03} \\
\hline & 2 & 88,05 & 88,85 & 89,59 & 90,53 & 90,05 & 89,93 & 89,50 & \\
\hline \multirow{2}{*}{ PB } & 1 & 21,66 & 17,14 & 13,74 & $9,92^{b}$ & $8,08^{b}$ & $10,42^{b}$ & $13,49^{b}$ & \multirow{2}{*}{10,33} \\
\hline & 2 & 21,19 & 15,47 & 15,35 & $14,39^{\mathrm{a}}$ & $11,80^{\mathrm{a}}$ & $15,23^{\mathrm{a}}$ & $15,57^{\mathrm{a}}$ & \\
\hline \multirow{2}{*}{ FDNc } & 1 & 50,31 & 45,01 & 56,48 & 60,86 & $70,99^{\mathrm{a}}$ & 66,39 & 58,34 & \multirow{2}{*}{5,24} \\
\hline & 2 & 44,57 & 50,68 & 60,88 & 59,81 & $62,84^{\mathrm{b}}$ & 64,91 & 57,26 & \\
\hline \multirow{2}{*}{ FDAc } & 1 & 26,69 & 26,01 & 31,82 & 32,22 & 36,91 & 35,80 & 31,57 & \multirow{2}{*}{4,98} \\
\hline & 2 & 24,74 & 27,82 & 32,46 & 32,78 & 36,79 & 35,41 & 31,66 & \\
\hline & 1 & 72,44 & 70,83 & 68,55 & 58,59 & 56,57 & 61,20 & $64,69^{b}$ & \\
\hline DIVMS & 2 & 77,33 & 75,15 & 70,74 & 68,42 & 60,62 & 61,54 & $68,96^{\mathrm{a}}$ & 5,52 \\
\hline DIVMO & 1 & $75,97^{\mathrm{b}}$ & 78,25 & 73,42 & 66,40 & 60,72 & 64,56 & 69,88 & \\
\hline DIVMU & 2 & $80,69^{\mathrm{a}}$ & 79,23 & 73,39 & 70,65 & 63,45 & 64,09 & 71,91 & 3,35 \\
\hline M & 1 & 86,05 & $83,27^{\mathrm{b}}$ & 86,35 & 89,40 & 91,96 & 89,83 & 87,75 & 177 \\
\hline MO & 2 & 87,99 & $88,41^{\mathrm{a}}$ & 88,86 & 89,45 & 89,68 & 89,60 & 89,00 & 1,77 \\
\hline & 1 & 18,78 & 16,90 & 15,70 & 12,29 & $8,50^{\mathrm{b}}$ & $12,76^{\mathrm{b}}$ & $14,15^{\mathrm{b}}$ & \\
\hline PB & 2 & 18,60 & 14,47 & 15,64 & 14,19 & $11,86^{\mathrm{a}}$ & $17,34^{\mathrm{a}}$ & $15,52^{\mathrm{a}}$ & 6,32 \\
\hline FDNc & 1 & 54,30 & 49,11 & 60,18 & 65,00 & 74,39 & 73,23 & 62,70 & 592 \\
\hline FDNC & 2 & 54,37 & 54,44 & 61,70 & 63,58 & 67,26 & 65,91 & 61,21 & 5,92 \\
\hline FחA & 1 & 28,30 & 26,84 & 30,08 & 32,76 & 38,92 & 36,78 & 32,28 & 6.15 \\
\hline FDAC & 2 & 28,01 & 28,51 & 30,93 & 32,08 & 36,70 & 36,07 & 32,05 & 6,45 \\
\hline DIMS & 1 & 69,64 & 66,61 & 65,28 & 68,14 & $64,57^{\mathrm{a}}$ & 64,23 & 66,41 & \\
\hline DIVMS & 2 & 73,30 & 66,66 & 65,64 & 65,58 & $56,51^{b}$ & 68,08 & 65,95 & 6,47 \\
\hline & 1 & 66,49 & 68,88 & 70,35 & 72,20 & $67,78^{\mathrm{a}}$ & 63,30 & 68,16 & \\
\hline DIVMO & 2 & 76,97 & 71,12 & 69,45 & 69,32 & $61,51^{\mathrm{b}}$ & 70,69 & 69,84 & 7,90 \\
\hline
\end{tabular}

1SF1 = capim elefante (CE) + azevém $(\mathrm{AZ})$ + espécies de crescimento espontâneo (ECE) + trevo branco (TB); SF2 = CE + AZ + ECE + amendoim forrageiro (AF). CV = Coeficiente de variação. 'a b’ médias seguidas por letras distintas, na coluna, diferem entre si $(\mathrm{P}<0,05)$. Total $(\mathrm{Capim}$ elefante + forragem presente na entrelinha). 
A participação do azevém, das leguminosas e das espécies de crescimento espontâneo é importante para manter a oferta de forragem (lâminas foliares), pois compensa o declínio natural da produção do capim elefante. Comparativamente, verificou-se melhor distribuição de forragem do amendoim forrageiro em relação ao trevo branco no decorrer das avaliações.

O valor nutritivo é similar entre os pastos, devido à complementaridade proporcionada por forrageiras dos ciclos hibernal e estival. A maior participação do amendoim forrageiro na composição do pasto implica maior teor proteico da forragem.

\section{COMITÊ DE ÉTICA E BIOSSEGURANÇA}

Protocolo 23081016073/2011-27. Parecer 113/2011.

\section{REFERÊNCIAS}

AOAC (ASSOCIATION OF OFFICIAL ANALYTICAL CHEMISTS). Official methods of analysis. 14.ed. Arlington, Washington, USA, 1984. 1094p.

ASSMANN, A.L. et al. Produção de gado de corte e acúmulo de matéria seca em sistema de integração lavoura-pecuária em presença e ausência de trevo branco e nitrogênio. Revista Brasileira de Zootecnia, v.33, n.1, p.37-44, 2004. Disponível em: <http:// www.scielo.br/scielo.php?script=sci_arttext\&pid=S151635982004000100006\&lng=pt\&nrm=iso $>$. Acesso em: 15 abr. 2008. doi: 10.1590/S1516-35982004000100006.

CADISCH, G. et al. Nitrogen cycling in a pure grass pasture and a grass-legume mixture on a red Latossol in Brazil. Tropical Grasslands, v.28, n.1, p.43-52, 1994. Disponível em: <http:// www.ufrrj.br/posgrad/cpz/forragem/10.pdf>. Acesso em: 17 ago. 2008.

COMISSÃO DE QUÍMICA E FERTILIDADE DO SOLO CFSRS /SC. Manual de recomendação de adubação e calagem para os Estados do Rio Grande do Sul e Santa Catarina. 10.ed. Porto Alegre, SBCS/ NRS, 2004. 400p.

EUCLIDES, V.P.B. et al. Avaliação de diferentes métodos de amostragem para se estimar o valor nutritivo de forragens sob pastejo. Revista Brasileira de Zootecnia, v.21, n.4, p.691702, 1992. Disponível em: <http://www.revista.sbz.org.br/artigo/ visualizar.php?artigo=724>. Acesso em: 13 ago. 2012. doi: S1516-3598200600020003.

GONZALEZ, M.S. et al. Produción de leche en pasturas de estrella africana (Cynodon nlemfuensis) solo y associado on Arachis pintoi o Desmodium ovalifolium. Pasturas Tropicales, v.18, n.1, p.212, 1996. Disponível em: <http://ciat-library.ciat.cgiar.org/ Articulos_Ciat/Vol18_rev1_a\%C3\%B1096_art2.pdf >. Acesso em: 13 ago. 2012

LOURENÇO, A.J. et al. Estudo comparativo entre três níveis de fertilização nitrogenada e consorciada com leguminosas em pastagens de capim-elefante napier (Pennisetum Purpureum Schum.) na determinação da capacidade de suporte. Boletim da Indústria Animal, v.35, n.1, p.69-80, 1987.
MEINERZ, G.R. et al. Composição nutricional de pastagens de apim-elefante submetido a duas estratégias de manejo em pastejo. Acta Scientiarum Animal Science, v.30, n.4, p.379- 385, 2008. Disponível em: <http://periodicos.uem.br/ojs/index.php/ ActaSciAnimSci/article/view/3476/3476>. Acesso em: 20 set. 2008. doi: 10.4025/actascianimsci.v30i4.3476.

OLIVO, C.J. et al. Produtividade e valor nutritivo de pasto de capimelefante manejado sob princípios agroecológicos. Revista Brasileira de Zootecnia, v.36, n.6, p.1729-1735, 2007. Disponível em: <http:/ /www.scielo.br/scielo.php?script=sci_arttext\&pid=S1516$35982007000800004 \& \operatorname{lng}=$ pt\&nrm=iso>. Acesso em: 30 nov. 2008. doi: 10.1590/S1516-35982007000800004.

OLIVO, C.J. et al. Valor nutritivo de pastagens consorciadas com diferentes espécies de leguminosas. Revista Brasileira de Zootecnia, v.38, n.8, p.1543-1552, 2009. Disponível em: <http://www.scielo.br/scielo.php?script=sci_arttext\&pid=S151635982009000800019\&lng=pt\&nrm=iso >. Acesso em: 25 set. 2008. doi: 10.1590/S1516-35982009000800019.

PERIN, A. et al. Desempenho de algumas leguminosas com potencial para utilização como cobertura viva permanente de solo. Agronomia, v.34, n.1-2, p.38-43, 2000. Disponível em: <http://docsagencia.cnptia.embrapa.br/agriculturaOrganica/ Desempenho_Cobertura_Viva.pdf>. Acesso em: 13 jun. 2008.

RAO, I.M.; KERRIGE, P.C. Mineral nutrition of forage Arachis. In: KERRIGE, P.C.; HARD, B. (Eds.). Biology and agronomy of forage Arachis. Cali: CIAT,1994. p.53-70.

RESTLE, J. et al. Produção animal em pastagem com gramíneas de estação quente. Revista Brasileira de Zootecnia, v.31, n.3, supl, p.1491-1500, 2002. Disponível em: <http:// www.scielo.br/scielo.php?script $=$ sci_arttext \&pid=S151635982002000600021\&lng $=p t \& n r m=i s o \& t \operatorname{lng}=p t>$. Acesso em: 03 ago. 2008. doi: S1516-35982002000600021.

SANTOS, H.P. et al. Principais forrageiras para integração lavoura-pecuária, sob plantio direto, nas Regiões Planalto e Missões do Rio Grande do Sul. Passo Fundo: Embrapa Trigo, 2002. 142p.

SAS INSTITUTE, SAS. Statistical analysis user's guide. Version 8.2. Cary, 1997. 1686p.

SCHEFFER-BASSO, S.M. et al. Desempenho de leguminosas nativas (Adesmia) e exóticas (Lotus, Trifolium), em função do estádio fenológico no primeiro corte. Revista Brasileira de Zootecnia, v.34, n.6, p.1871-1880, 2005. Disponível em: $<$ http://www.scielo.br/scielo.php?script=sci_arttext\&pid=S151635982005000600010\&lng=pt\&nrm=iso\&tlng $=\mathrm{pt}>$. Acesso em: 17 ago. 2008. doi: 10.1590/S1516-35982005000600010.

SOBCZAK, M.F. et al. Evaluation of an elephantgrass pasture mixed with black oat managed under agro-ecological principles in winter period. Livestock Research for Rural Development, v.17, n.6, 2005. Disponível em: <http:// www.lrrd.org/lrrd17/6/fati17071.htm>. Acesso em: 07 ago. 2010.

THOMAS, R.J. The role of the legume in the nitrogen cycle of productive and sustainable pastures. Grass and Forage Science, v.47, n.2, p.133-142, 1992. Disponível em: <http:// onlinelibrary.wiley.com/doi/10.1111/j.1365-2494.1992.tb02256.x/ abstract>. Acesso em: 24 ago. 2008. doi: 10.1111/j.13652494.1992.tb02256.x. 
TILLEY, J.M.A.; TERRY, R.A. A two-stage technique of the in vitro digestion of forage crop. Journal of British Grasslands Society, v.18, n.2, p.104-111, 1963.

TOWNSEND, C.R. et al. Desempenho de novilhas da raça Holandesa em cultivares de capim-elefante Pennisetum purpureum Schum.). Ciência Rural, v.24, n.2, p.381-386, 1994.
VAN SOEST, P.J. et al. Methods for dietary fiber, neutral detergent fiber, and nonstarch polysaccharides in relation to animal nutrition. Journal of Dairy Science, v.74, n.1, p.35833597, 1991.

WILM, H.G. et al. Estimating forage yield by the double sampling method. Journal of American Society of Agronomy, v.36, n.1, p.194-203, 1944. 